\title{
LO PERSONAL HUMANO COMO MODALIDAD DE SIMBOLO
}

\author{
DR. FERMANDO OYARZUN $P$. \\ Psiquiatra \\ Universidad Austral de Chile. \\ Valdivia-Chile.
}

I. LA PERSONALIZACION COMO PECULIAR SIMBOLIZACION.

\begin{abstract}
El hecho de considerar el proceso personalizador como simbolización, sitúa a la idea de la persona en un plano primordial de relaciones, como es el propio del dinamismo simbólico, previo a los niveles lógico-racional y reflexivo-epistemológico (1). Su manifestación fenoménica es la expresividad personal (o lo expresivo-comunicativo fisonómico-simbólico). Acaso sea paradójico que un todo significativo implícito, subyacente, básico, se de en una parte explícita, palpable, patente. Por ejemplo, una biografía personal constituida por un conjunto de situaciones amargantes, experimentadas en el pasado, y que se muestran en un gesto amargo, o en el tono de voz, 0 en un vocablo encarnando amargura. (Estimo que lo común entre tales planos es el componente fisiognómico, el cual es característica esencial del pensamiento místico) (2) (Tales planos fenomenológicos constituyen una misma estructura de sentido).
\end{abstract}

En la simbolización personal se dan dos dialécticas principales, constituyendo ambas una sola estructura de sentido y modificándose recíprocamente. Ellas son: a) la bipolaridad mundo-sujeto y b) la bipolaridad psico-corporal. Esta estructura es lo dado en el fenómeno manifestativo antes nombrado; es decir, en la expresividad personal. Esta entraña, en efecto, el modo vivo, corporeizado, como una persona experimenta su mundo. 
CULTURA, HOMBRE, SOCIEDAD.

$(2.2 .1985$

Como vemos, lo psíquico, que corresponde al significado de la situación mundo-sujeto, es corporeizado, constituyéndose en significado vivido, deviniendo el sentido personal que encarna en el fenómeno expresivo-comunicativo. De aquí pueden ser inferidos dos caracteres, también básicos, del proceso personalizador entendido como simbolización. Por una parte, la dialéctica incompletud-completud, siendo esto propio de la idea arcaica de lo simbólico (3) (el concepto griego de symballon). En seguida, la propiedad del símbolo personal de presentar y representar como forma significativa (entrañando sentido) a 10 simbolizado. (En la relación desde y hacia el otro personal, en este acto personal, el fenómeno transfigurativo acusa, por un lado, el momento integrativo -tránsito desde lo incompleto a lo completoy por otro, el hecho que expresa y comunica el modo de configurarse la relación de sentido entre ambas partes). (Los caracteres señalados marcan diferencias cualitativas con el signo: éste es una mera señal de otra cosa, no siendo ésta parte complementaria de aquello, y tampoco hay parentesco fisonómico entre ambas. El signo no es un significado vivo, corporeizado; por ende, carece de forma viva, no constituyendo una estructura de sentido como sucede con el símbolo).

En el curso de su desarrollo biográfico, el ser personal se va estructurando mediante la apropiación del mundo, estando esta polaridad mundana constituida principalmente por los otros seres personales. Este proceso apropiador va resultando por la confluencia dialécticamente complementaria, de dos movimientos transformadores. En primer término, por la "incorporación" del polo del mundo (fundamentalmente de otras figuras personales). Ahí lo psíquico se une a lo corporal y se produce, siguiendo esta dirección centrípeta, la unión dialéctica transformadora de 10 ajeno y 10 propio. La resultante transfiguración del sujeto patentiza la génesis de esta simbolización personal; es decir, ésta última se manifiesta fenoménicamente en la expresividad comunicativa que, como vemos, entraña la unión de ambas polaridades y atestigua el hecho que lo fenoménico simbólico representa y presenta a dicha estructura de sentido. 
El proceso descrito se cumple en todo acto de relación personal, en general, y por modo particularmente intenso en relaciones como la del niño con sus padres y otras figuras personales formadoras; o del estudiante con su profesor. Estas incorporaciones apropiadoras se emparentan con las denominadas identificaciones por la psicología dinámica. La resultante en el niño o en el estudiante no es convertirse, sin embargo, en alguien idéntico al modelo, sino que es una transformación en que se sintetizan dialécticamente lo ajeno y 10 propio, haciéndose así parecido a la figura-modelo, a la vez que diferente, siendo ambos aspectos igualmente importantes en el proceso personalizador.

En segundo término, el señalado proceso apropiador se verifica mediante la "corporalización" del polo del mundo, sintetizándose también, dialéctica y transformadoramente lo propio y ajeno, esta vez en dirección centrífuga, verificándose, al mismo tiempo, la síntesis dialéctica de lo psíquico y 10 corporal, gestándose la unión simbólica del uno en el otro.(El hijo en el padre, el estudiante en el profesor, el paciente en el médico y viceversa, etc.).

El resultado del proceso transformador en las dos direcciones de sentido señaladas, es la configuración de una compleja estructura de sentido integrado por mundo y sujeto, por el otro y el uno personales. En suma, se configura el ser personal que, como vemos, resulta una unidad plenamente simbóli$c a, y$ en que sujeto y mundo se co-determinan, constituyendo un solo todo psico-corporal.

Como podrá advertirse, en este proceso de personalización, entendido como simbolización, el sujeto se "mundaniza" y el mundo se "subjetiviza" (integración dialéctica mundo-sujeto); el componente "psíquico" (significado de la situación) se "corporaliza" y el cuerpo se "animiza", pasando a constituir, mediante estas transformaciones, realidades nuevas, simbólicas, sintesis dialécticas que no se reducen a ninguna de las partes por separado. Podrá observarse, asimismo, como estas uniones 
transformadoras cristalizan en el fenómeno expresivo personal que, por lo tanto posee una naturaleza plenamente simbólica.

\section{DIALECTICA DE NORMALIDAD-ANORMALIDAD PERSONALES.}

En el ámbito médico-antropológico, en grado muchísimo mayor que en cualquier otro campo de la antropología, es indudable que el tema de las relaciones entre lo sano y lo enfermo, lo normal y 10 anormal, adquiere una importancia relevante. De aquí deriva, con seguridad, la significación asimismo primordial de las relaciones psico-corporal, o mente-cuerpo, ya que no cabe concebir lo mórbido sin el compromiso de ambos componentes. A todo esto no es ajeno una psicopatología antropológicamente orientada. En ésta son igualmente importantes tanto lo psíquico (significado de las situaciones vitales) como lo corporal (cuerpos físico y vivido), de cuya unión dialéctica nace el sentido personal (significado vivido o corporeizado).

El fenómeno psicopatológico personal, presente en modalidades propias en los distintos pacientes, se nos muestra - expresivo comunicativamente, en lo principal, por desarmonía o falta de adecuada concordancia entre los aspectos de contenido verbal en que son vehiculizados la significación y el sentido de lo que el paciente vivencia (situaciones biográficas), representando tales significados el componente denominado "psíquico", y los aspectos fisionómicos que lo acompañan (tono y timbre de la voz, semblante del rostro, modo de la mirada, mímica manual, postura corporal, modos de estar sentado y caminar; en suma, la configuración expresivo-comunicativa, representando todas estas manifestaciones el componente corporal). Esta desarmonía o discordancia psico-corporal, es una alteración simbólica, una relación disociada de esta estructura dialéctica. Es la contrafigura de la manifestación fenoménica de una persona normal, en que el proceso de personalización o simbolización se desarrolla satisfactoriamente. 
Esta alteración expresivo-comunicativa, presenta y representa, en tanto forma significativa, al modo alterado de la relación del sujeto con el mundo; a la falta de unión armónica, concordante de ambas polaridades. En el ámbito más específicamente humano, que es directa 0 indirectamente, explícita 0 implícitamente, perceptiva o imaginativamente, interhumano, presenta y representa a la relación el otro-el uno personales. Dicha expresividad desempeña, a su vez, el papel de símbolo de esta última estructura de sentido que corresponde a lo simbolizado. (Lo biográfico personal, con sus componentes pasado, presente y futuro, constituye una compleja configuración significativa, integrada por múltiples bipolaridades corporeizadas en que encarnan las situaciones vividas por la persona).

En lo esencial, en dicha relación de sentido mundosujeto, éste no está efectuando de manera satisfactoria a sus procesos de "incorporación" y "corporalización". -momentos apropiadores o simbolizadores- con lo cual se está desapropiando del mundo, empobreciéndose al no recibir la influencia formadora y transformadora de esta fuente de sentido y al no trascenderse creadoramente en ella.

A manera de ejemplificación ilustrativa de 10 expuesto, cabe citar las modalidades psicopática antisocial, neurótica hipocondríaca y psicótica esquizofrénica de alteración personal.

Así, en el paciente psicopático antisocial, la descarnada verbalización (peculiar ruptura de la unión simbólica de los aspectos formales, fisionómicos, y de contenido verbal, disociación psico-corporal), simboliza, en especial, la desconsideración del polo del mundo objetivo, del otro como ser personal (peculiar ruptura de la unión simbólica el otro-el uno personales). Esto implica una falta de apropiaciones incorporadoras y corporalizadoras. (Las experiencias vitales resbalan; son personas abiográficas). Lo anterior se corresponde con la falta de una adecuada conciencia del mundo (de éste como unidad simbólica). Esta cristaliza, a su vez, en una inadecuada actitud frente al otro -egocéntrica desconsideración, convirtiéndolo en 
medio y no en un fin- y frente a sí mismo: aceptación de su naturaleza más individual que personal. (La forma de conducta impulsiva tiende a sustituir a la forma considerada reflexiva).

En el paciente neurótico hipocondríaco, el énfasis formal, fisionómico, "notificativo", que no es concordante con el contenido significativo objetivo de la queja, simboliza la imaginativa distorsión del sentido del mundo subjetivo, corporal, lo que forma estructura de sentido con una correlativa hiperconsideración del otro personal en dirección ominosa. (Modo peculiar de ruptura de la unión simbólica el otro-el uno personales). Lo anterior implica una forma específica de alterarse su conciencia de realidad. Todo esto se corresponde con una actitud personal angustiosamente temerosa respecto del mundo objetivo y subjetivo, tendiendo y realizando absolutizaciones negativas, en dirección de lo peligroso.

En el paciente psicótico esquizofrénico, la discordancia entre los aspectos formales fisionómicos (falta de flexibilidad, plasticidad) y de contenido verbal (forma indicativa), simboliza la escisión mundo-sujeto por desfiguración del polo del mundo. Ello se corresponde con la alterada conciencia simbólica y cristalizando en actitudes patológicas, como por ejemplo, de ensimismamiento autístico (ello implica una progresiva desapropiación por falta de incorporación y desaparecimiento de corporalizaciones intencionales trascendentes). Ideas delirantes y alucinantes cristalizan las desintegraciones simbólicas.

En suma, podría afirmarse que las desarmonías simbólicas presentes en la expresividad personal y en la relación mundo-sujeto, en correspondencia con alteraciones de la conciencia y actitud personales, constituyen una sola estructura de sentido.

Es decir, cada miembro de la estructura está ligado por nexos estructurales íntimos o de sentido con los demás. Asj, los aspectos expresivo-comunicativos formales y de contenido sin duda constituyen un solo todo y se modifican mutuamente. 
Ellos expresan y comunican, o simbolizan, el modo como el sujet.o experimenta (respuesta anímico-vivencial) el mundo objetivo y subjetivo, lo que testimonia la comunidad de sentido de ambas bipolaridades. En seguida, tanto el acto de relación sujeto-mundo como el acto expresivo comunicativo, al producirse, generan un halo de conciencia al afectar retroactivamente al sujeto. La respuesta básica de éste a tal apariencia significativa cristali$z a$ en la actitud personal, ostensible a la percepción del otro, del observador y no, en cambio, a la auto apreciación.

A este último propósito, cabría agregar que, en la presente perspectiva en que reina el dinamismo de complejas transformaciones simbólicas, las relaciones entre lo conscienteno consciente configuran, también, una estructura dialéctica y no, en cambio, una relación lineal mecánica. Pudiera plantearse que en tanto las diversas bipolaridades significativas señaladas son suficientemente integrativas, predominará la polaridad de lo consciente sobre lo no consciente y viceversa.

La normalidad personal (personalización normal) se identifica con la armonía integrativa de las diversas polaridades y viceversa en la anormalidad personal (despersonalización).

\section{CONSIDERACIONES TEORICAS.}

Las características del proceso de simbolización normal o alterado lleva consigo implicaciones de diversa índole que procuraremos explicitar en seguida:

1) Desde luego, la relación dialéctica, transformadora, sujetomundo, el otro-el uno personales, y de lo psíquico y lo corporal, posee una naturaleza vivamente rítmica. Es decir, es una modalidad de movimiento transformador desplegado en el tiempo. Tanto la corporalización del polo objetivo o del mundo, como la incorporación subjetiva o íntima, ambos momen- 
CULTURA, HOMBRE, SOCIEDAD.

tos de flujo y reflujo apropiadores, poseen ritmicidad. Ello se acusa en la expresividad personal. Por tanto, la relación del uno desde y hacia el otro personal, necesita adquirir una armónica, rítmica sintonización, lo que se sostiene mediante un suficiente grado de mutua transfiguración.

2) En seguida, puede desprenderse del proceso personalizador descrito el que la conciencia personal, tanto respecto del mundo objetivo como subjetivo, nace del acto personal (interpersonal), como un proceso progresivo que se va gestando en el tiempo, en momentos sincrónico y diacrónico. Tal concienciación requiere de la relación corporeizada (unión psicocorporal), apropiadora, del sujeto personal con el mundo (relación "simpatética" (4) con el mundo). La conciencia personal y el yo personal mismo harían su aparición al verificarse el acto de relación reflexiva sobre el acto de relación previamente nombrado. Hay aquí implícita una dialéctica tanto temporal (de los momentos señalados) como espacial (los dos niveles señalados: el del acto de relación mundo-sujeto, el otro-el uno, y el acto de relación del sujeto reflexivamente con tal relación) (dentro del componente espacial, queda también comprendida la dialéctica cercanía-distancia; la relación situado el uno en el otro y Iuego distanciado, armonizándose las actitudes empática y de objetividad, el ser como el otro, parecerse, y diferenciarse).

3) En tercer término, los valores humanos son, también, componentes que integran al todo de sentido implícito o latente (lo simbolizado), pudiendo ser develados. En rigor, son vigentes implícitamente las actitudes valorativas. De ahí que la persona psicopatológicamente alterada, víctima de un proceso de despersonalización, nos muestra la pérdida de la vigencia adecuada de esos valores, por modos diferentes según las distintas formas del proceso despersonalizador.

Lo anterior se verifica primordialmente en el nlano 
interexpresive-comunicativo fisonómico-simbólico, donde empieza a darse la unión interpersonal o simbólica. Porque, en efecto, aquí reinan lo vivo, lo ético, lo verdadero, ?.0 libre y 10 creador. A propósito de lo vivo: así como con razón se dice que sólo lo vivo tiene rostro, (5) vale decir, expresivinad personal, cabe afirmar que no hay rostro personal carente de vivacidad y plasticidad, normal 0 alterada. Lo ético, ya que la base esencial de sustentación de una adecuada actitud ética es la conciencia del otro como ser personal; es decir, como alguien que debe ser considerado como un fin y no como un medio. En el primer caso, hay la consideración del otro con suficiente independencia de los. intereses propios, al mismo tiempo que en armónica relación de sentido con uno, formando una estructura de sentido común. En el segundo caso, queda suprimido el primer componente. (La síntesis dialéctica mundo-sujeto, el otro-el uno personales y la unión psico-corporal, determinan una estructura de sentido. Y es propio de ésta que cada miembro integrante sea una unidad dialéctica parte-todo, a la vez independiente y dependiente de la estructura. Así, el otro personal pertenece a la estructura de sentido conjuntamente con el uno personal, pero al mismo tiempo forma parte de otras estructuras de sentido. Por esto, si el otro personal es integrante de tales estructuras, se crea la base para una actitud éticamente adecuada, lo que no sucede, en cambio, cuando no es experimentado de ese modo, dejando de estimárselo como persona).

Lo verdadero, es decir, la capacidad de tener mundo objetivo, de aprehender los significados de las situaciones (que, en el nivel del sentido aprehenden en bipolaridades significativas, es decir, en unidades simbólicas), también se desprende del desenvolvimiento de una adecuada personalización ajena y propia. La personalización lleva consigo un satisfactorio estado anímico, favorecedor de un suficiente grado de integración (integración simbólica) que permite una adecuada aprehensión simbólica. En caso contrario, se producirá una diafragmada manera de captar tales significados, a 
la vez que distorsiones del sentido. Esto facilita el surgimiento de actitudes reificadoras y personificadoras, como sucede, por ejemplo, paradigmáticamente, a la persona angustiada (actitud imaginativa catastrofista, en que se da la extrapolación absolutizadora negativa, en sentido de 10 peligroso; o la cristalización fóbica, que es asimismo una modalidad de simbolización anormal).

Lo estético, en que la relación rítmica, armoniosamente sintónica requiere, también un adecuado partir desde y hacia el otro, lo que implica la satisfactoria relación dialéctica de las dos polaridades y la unión simbólica psico-corporal. En el fenómeno transfigurativo recíproco, lo corporal se "interpersonaliza" y 10 interpersonal se "corporaliza", todo 10 cual representa un conjunto de complejas, enriquecedoras transformaciones simbólicas.

Lo libre, en la medida en que el ejercicio de un acto libre requiere de un grado suficiente de integración personal, implicando autodominio y superación de actitudes temerosas, inhibidoras. Aquella integración personal requiere de la influencia unificadora del polo del mundo; en la situación interhumana, del otro personal.

Y lo creador, componente de valor puesto en vigencia en las enriquecedoras transformaciones dialécticas antes descritas, siendo esto también propio del proceso de personalización, cuya fuente es 10 interhumano entendido en el plano primordial de la recíproca simbolización, existiendo la posibilidad contrapuesta de la mutua despersonalización entendida como desimbolización. La personalización de sí es creación de sí mismo; la despersonalización, un proceso de progresiva desctrucción propia.

4) La orientación científico-personal. Como veíamos, el hecho psicopatológico, entendido como alteración personal (despersonalización, desimbolización) se manifiesta fenoménicamente en la alterada expresividad personal (comunicativa fisonómico- 
'simbólica). Esta expresividad es una estructura de sentido, como veíamos, y en que pueden ser distinguidos aspectos de forma (10 fisonómico, lo verbal encarnado sentido) y de contenido (contenidos verbales que vehiculizan, además, significados referenciales). Ambos componentes constituyen una unidad simbólica, como señalamos previamente.

Las antedichas características fenoménicas del objeto (sujeto anormal), obligan a asumir una actitud fenomenológica con que deberá aprehenderse viva, corporeizadamente, el sentido de 10 manifestado con sus componentes de forma y contenido. (estos pueden darse armónica o disarmónicamente; en movilidad dialéctica de cercanía y distancia, conduciendo a transformaciones enriquecedoras o a desfiguraciones empobrecedoras. En virtud de la transformación recíproca de ambas polaridades, asemejándolas, se produce cercanía (aspecto espacial) y simultaneidad temporal; en virtud de la diferencia que persiste no obstante lo anterior (dialéctica de componentes semejanza-diferencia), se produce distancia y no simultaneidad temporal. Ambos aspectos poseen decisiva importancia en el proceso de personalización (despersonalización) en que se unen dialécticamente ser y devenir, es decir, momentos integrativos sincrónico y diacrónico.

En tanto el objeto (sujeto-paciente) es fenoménicamente una viva, corporeizada forma expresivo-comunicativa, la respuesta fenomenológica deberá ser, también, una viva, corporeizada, forma expresivo-comunicativa en que transfigurativamente se acusa el cambio concordante. Y por tratarse de una estructura de sentido dialéctica simbólica, la respuesta debe ser correlativamente simbólica, en que se armonicen integrativamente aspectos de forma y contenido. El médico no sólo deberá realizar el acto de relación pacientemédico (mundo-sujeto) y el acto expresivo-comunicativo en los términos señalados, sino que, también, deberá adquirir suficiente conciencia de ello y de su actitud asumida respecto del paciente y de sí mismo. 
Además, es necesario que el observador vaya desde el símbolo a lo simbolizado (desde la parte patente al todo latente, desde 10 que se ve 0 aparece a 10 que se trasve 0 trasparece); o sea, desde la forma expresiva personal a la estructura de sentido a la que pertenece, presentándola y representándola. Esto es la actitud y acción propias de una fencmenología hermenéutica o personal. (6)

Como podrá ser advertido, el proceso metodológico anterior no sólo ha significado la personalización del objeto (sujeto-paciente), sino que a la vez ha conducido a la personalización del observador. Por ello, esta fenomenología personal o simbólica requiere y permite unir dialécticamente los componentes de conocer y ser del acto personal médico, evitando no sólo la impersonalización del paciente, sino también del médico, lo que tenderá a suceder cuando la actitud y acción médicas se reduzcan a sólo un conocimiento operativo del padecer del enfermo.

Lo que hemos desarrollado correspondería a üna aproximación científica en el estudio de lo personal humano, entendido éste como de naturaleza simbólica, normal y anormal. El objeto personal o simbólico configura el método personal o simbólico. El modo de la generalización, abstracción o conceptuación debe acomodarse a la legalidad del dinamismo de interacciones transformadoras simbólicas antes descrito; a la extensión y límites del conocer y hacer; a los modos diferentes y complementarios de entender significaciones referenciales, impersonales, y aprehender el sentido personal de los fenómenos.

Dentro del presente contexto teórico, el modo de conocer va íntima, estructuralmente ligado al actuar y, con ello, al ser, es decir, al constituir y constituirse como ser personal (o estructura de sentido, dialéctica, simbólica). Esto es cualitativamente diferente a un conocer y conceptuar meramente racionales que, por prescindir del componente del ser (constituir y constituirse), resulta un acto 
Oyarzún) LO PERSONAL HUMANO COMO MODALIDAD DE STMBOLO

impersonal e impersonalizante del objeto por conocer (el paciente como un peculiar otro personal) y del sujeto cognoscente (el médico como peculiar uno personal). Quizás pudiera sostenerse que las bases conceptuales expuestas, junto a otras, porporcionan fundamento de una antropología médica y psicopatológica suficientemente concreta, respetándose el hecho básico de la diferencia entre un conocer de una cosa, objeto impersonal, y de un ser personal.

Esta orientación científico-personal es diferente esencialmente a las orientaciones científico-natural y científico-cultural ad usum. Lo es porque estas últimas se mueven en el plano de las significaciones referenciales, impersonales, y no, en cambio, en el nivel del sentido. Aquel significado es ajeno al componente formal; a las formaciones y transformaciones. Ellas se preocupan de establecer relaciones generales abstractas, desentendiéndose del ser en 10 que éste tiene de singular y concreto; se les escapa la naturaleza simbólica de lo personal humano. Por el contrario, lo científico personal aquí propuesto tiene como punto de partida un objeto cuya naturaleza estructural es simbólica, dialéctica y que se da fenoménicamente. Ello condiciona un método fenomenológico hermenéutico (simbólico, personal). Este permitirá siempre develar la estructura de sentido a la que la forma fenoménica (fenómeno expresivo, comunicativo, fisonómico simbólico) pertenece y representa. Aquí hay una universalidad metódica: cada vez que los observadores proceden hermenéuticamente, develarán dicha estructura. Agréguese que una actitud similar es asumida por el observador respecto de sus propios cambios (conciencia personal o simbólica de sí), suscitados por la presencia personal del paciente. Aquí se advierte cómo el conocer va ligado intimamente al hacer y al ser personales, lo que no ocurre con los otros enfoques científicos.

De esta manera, por otra parte, se evita la sustantivación, reificación o personificación de los que son componentes de una estructura de sentido, normal o anormal, y no 
CULTURA, HOMBRE, SOCIEDAD.

son, en cambio, entes dueños de individualidad y vida propias. Esto último sucede cuando el contexto o marco referencial es el individual ("sujeto de piel hacia adentro") (estratos o componentes de la personalidad), y no el contexto de sentido o nivel de lo personal.

\section{RESUMEN.}

1. Se empieza afirmando que, por identificar la idea de persona (personalización) como una modalidad de simbolización, el presente planteamiento compromete un plano primordial de relaciones, previo al lógico y epistemológico. (Nivel de la relación dialéctica, transformadora, simbólica, dada fenoménicamente en lo expresivo comunicativo fisonómico).

2. En dicha personalización o simbolización se dan dos dialécticas principales, constituyendo una sola estructura de sentido: las bipolaridades mundo-sujeto y psico-corporal, dándose en la expresividad personal.

3. El significado de la situación mundo-sujeto (componente psíquico) es corporeizado, constituyéndose en el sentido personal. También puede desprenderse de 10 anterior dos caracteres básicos de la personalización o simbolización: dialéctica de incompletud-completud (ligado al concepto arcaico, griego de símbolo) y la propiedad del símbolo personal (forma significativa) de representar a lo simbolizado (similitud fisonómica), siendo ambos caracteres ajenos al signo.

4. Respecto de la intimidad del proceso personalizador, se hace ver que en el curso de su desarrollo, el ser personal se va apropiando del mundo (especialmente de otros seres personales). Ello se haría a expensas de dos movimientos transfor- 
madores: 1) "incorporación" del polo del mundo (unión psicocorporal, síntesis trasnformadora de 10 ajeno y 10 propio) (Ejs.: relación integradora padre-hijo, profesor-estudiante, médico-paciente, etc.). 2) "corporalización" del polo del mundo (gestándose las mismas síntesis anteriores en esta dirección centrífuga). Así se iría constituyendo la estructura de sentido mundo-sujeto, o mundo personal.

5. Se hace notar que el problema de las relaciones entre la normalidad y anormalidad, en ámbito médico antropológico, posee una importancia fundamental. De ahí que una concepción de 10 personal humano, en este contexto, no puede desconsiderar las relaciones psico-corporal y mundo-sujeto.

6. La alteración personal se hace presente expresivo-comunicativamente en una disarmonía o falta de concordancia entre los aspectos de contenido verbal y los aspectos fisonómicos que lo acompañan, empezando por el tono de voz y toda la figura expresivo-comunicativa. Tal disarmonía es una disociación de la unión dialéctica, simbólica. Esta se corresponde con la forma de la alteración mundo-sujeto (el otro-el uno personales), en que no se verifican satisfactoriamente los antes descritos procesos apropiadores de incorporación y corporalización.

7. Por modo de ejemplificación, se citan las modalidades de alteración personal psicopática antisocial, neurótica hipocondríaca y psicótica esquizofrénica. En la primera: "desccarnada" verbalización simboliza la desconsideración del polo del mundo objetivo, del otro como persona. Ello implica una forma de desapropiación incorporadora y corporalizadora. Esto se corresponde con una inadecuada conciencia del mundo, cristalizando en una actitud radicalmente desconsiderada frente al otro (medio y no fin, postura antiética) y sentimiento implícito del sí individual, no personal. En la segunda: discordancia entre el énfasis formal, fisonómico y el contenido significativo objetivo de la queja, simbolizando la distorsión imaginativa del sentido del mundo subjetivo, 
CULTURA, HOMBRE, SOCIEDAD.

corporal, en correspondencia con una hiperconsideración ominosa del otro personal. Queda implicada una especifica, alterada conciencia de realidad y una actitud personal angustiosamente temerosa respecto del mundo, surgiendo absolutizaciones negativas, en dirección de lo angustiosamente peligroso. En la tercera: la discordancia entre los aspectos formales fisonómicos (peculiar rigidez) y de contenido verbal, simboliza la escisión mundo-sujeto por desfiguración del polo del mundo. Ello en correspondencia con alteraciones de la conciencia y actitud simbólicas 0 personales.

En síntesis: las rupturas o disarmonías simbólicas presentes en la expresividad personal y en la relación mundo-sujeto, y las ajteraciones de la conciencia y actitud personales, constituyen una sola estructura de sentido. La normalidad personal (personalización o simbolización normales) se identifica con la armonía integrativa de las diversas polaridades; viceversa en la anormalidad personal, (despersonalización-desimbolizaciones).

8. Finalmente, son explicitadas algunas implicaciones del proceso de personalización: a) modalidad de movimiento transformador dueño de ritmicidad, acusada en la expresividad personal, base de la necesaria sintonización en la relación desde y hacia el otro; b) la conciencia personal, nacida del acto personal, requiriendo la relación corporeizada, apropiadora, con el mundo ("relación simpatética"); c) valores humanos, en cuanto son inherentes al proceso de personalización actitudes valorativas fundamentales (alteradas en los pacientes despersonalizados). Así, lo vivo, en cuanto movilidad rítmica. Lo ético, en tanto, la base esencial de sustentación de una adecuada actitud ética es la conciencia del otro como ser personal. Lo verdadero, es decir, la capacidad de aprehender los significados de las situaciones que representan unidades simbólicas (ello se altera en la persona angustiada, p.ej.). Lo estético, en que, por ejemplo, la relación armoniosa requiere, también, un adecuado partir desde y hacia el otro, implicándose la unión dialéctica de 
ambas polaridades y psico-corporal. Lo libre, en tanto un acto libre requiere un grado suficiente de integracicin personal. Y lo creador propio de las transformaciones dialéc;ticas enriquecedoras antes descritas, sucediendo lo contrario en la despersonalización.

Por último, relativo a la orientación científico-personal, se afirma que la alteración personal se muestra fenoménicamente en la alterada expresividad personal, en sus componentes de forma y de contenido, integrantes de una unidad simbólica. Tales características del objeto, obligan a asumir una actitud fenomenológica con miras a aprehender vivo, corporeizadamente el sentido en aquella encarnado. La respuesta fenomenológica deberá ser, también, una viva, corporeizada forma expresivo-comunicativa, encarnando el cambio concordante; y correlativamente simbólico, armonizándose integrativamente aspectos de forma y contenido. El médico adquirirá suficiente conciencia de ello y de su actitud respecto del paciente. La acción fenomenológica irá desde el símbolo a lo simbolizado; o sea, desde la forma expresiva personal a la estructura de sentido a lo que pertenece (fenomenología hermenéutica). Se hace notar que, así, se ha ido desarrollando una mutua personalización, en que se unen dialécticamente conocer y ser, siendo esto propio de una orientación científico personal que pudiera considerarse específico del estudio de lo personal humano alterado, y asimismo propio de una antropología médica suficientemente concreta. 
CULTURA, HOMBRE, SOCIEDAD.

BIBLIOGRAFIA.

CASSIRER, Ernst Antropología Filosófica. Fondo de Cultura Econónima, 1983, Primera reimpresión en España.

herRera, J. y ESPINOZA, N. "Notas para una Fenomenología de la Despersonalización". Cuadernos de Psiquiatría, Números 5-6., Mendoza, 1967.

LERSH, Ph. La Estructura de la Personalidad. Ed. Scientia, Barcelona, 1958.

NICOL, Eduardo Metafísica de la Expresión. Fono de Cultura Económica, México, 1957.

NICOL, Eduardo Los Principios de la Ciencia. Fondo de Cultura Económica, México, 1975.

OYARzun, Fernando La Persona Humana y la Antropología Médica. Ed. Universitaria, Santiago, 1983. 